\title{
Effect of Haloperidol on Measures of Craving and Impaired Control in Alcoholic* Subjects
}

\author{
Jack G. Modeil, James M. Mountz, Frederick B. Glaser, and Jeannette Y. Lee
}

\begin{abstract}
We recently proposed that alcoholics suffer from a functional defect within the basal ganglia/limbic striatum or its modulation by dopaminergic projections from the ventral tegmentum, and that inhibition of striatal output caused by the prodopaminergic effects of alcohol ingestion induces or exacerbates craving and impaired control over alcohol consumption in alcoholic individuals. To test this hypothesis, 16 subjects with a diagnosis of alcohol dependence of abuse were studied in a double-blind, placebo-controlled experiment in which the effects of the D-2 antagonist haloperidol on measures of craving and impaired control were assessed before and after administration of a priming dose of alcohol. Subjects were pretreated with $0.015-$ $0.025 \mathrm{mg} / \mathrm{kg}$ haloperidol (experimental condition) or $2 \mathrm{ml}$ normal saline (control condition), and subsequently consumed $0.4-0.6 \mathrm{~g} / \mathrm{kg}$ ethanol as their preferred alcohol-containing beverage. Significant increases in subjectively rated craving for alcohol and perceived difficulty resisting additional alcohol consumption occurred following the priming dose of alcohol when subjects were pretreated with saline. In contrast, no significant changes in reported ability to resist additional alcohol occurred when subjects were pretreated with haloperidol, and reported levels of craving decreased relative to baseline following haloperidol pretreatment. Subjects also consumed about $25 \%$ less optionally available alcohol when pretreated with haloperidol than when pretreated with saline. These findings support the hypothesis that craving and impaired control are induced or exacerbated by the prodopaminergic effects of alcohol consumption.
\end{abstract}

Key Words: Dopamine, D-2 Antagonists, Basal Ganglia, Reinforcement, Alcohol Dependence.

M any individuals who have chronic, severe alcohol problems describe cravings or urges to drink that frequently lead to the perception of impaired control over

From the Departments of Psychiatry (J.G.M.), Radiology (J.M.M.), and the Comprehensive Cancer Center (J.Y.L.), University of Alabama School of Medicine, Birmingham, Alabama; and the Department of Psychiatry (F.B.G.), University of Michigan Substance Abuse Center, Ann Arbor, Michigan.

Received for publication July 7, 1992; accepted September 16, 1992

This study was supported by the National Institute of Health, Department of Research Resources Clinical Research Center Grants MO1RR00032 (University of Alabama) and MOI-RR00042 (University of Michigan).

* For purposes of simplicity and familiarity, the term "alcoholic(s)" will be used in this report to describe individuals who satisfy DSM-III-R criteria for alcohol dependence or alcohol abuse, and who experience obsession-like cravings or urges to drink and the perception of impaired control over alcohol consumption. It is, however, recognized that not all such individuals experience these phenomena and that this nonspecific, connotative term should ultimately be replaced by more descriptive terminology, even if initially somewhat more cumbersome to do so.'

Reprint requests: Jack G. Modell, M.D., Associate Professor of Psychiatry, Department of Psychiatry, University of Alabama School of Medicine, Smolian 402, UAB Station, Birmingham, AL 35294-0018.

Copyright 1993 by The Research Society on Alcoholism. alcohol consumption. In a recent review, ${ }^{2}$ we proposed that craving for alcohol and impaired control over its consumption in these individuals may result from a functional defect within the limbic striatum or its modulation by dopaminergic projections from the ventral tegmentum; and that inhibition of striatal output caused by the prodopaminergic effects of alcohol ingestion induces or exacerbates craving and impaired control over alcohol consumption in alcoholic individuals. The reader is referred to this review for a detailed discussion of the background and support for this hypothesis. Excellent overviews by $\mathrm{Koob}^{3}$ of the anatomy, pharmacology, and function of reward pathways, and by Samson et $\mathrm{al}^{4}$ of the role of mesolimbic dopamine in ethanol self-administration also provide very useful background material.

Our review of the literature supported the hypothesis that alcoholics (see footnote to title) may suffer from a neurophysiological dysregulation such that:

I. (1) Craving for alcohol or obsession-like thoughts about drinking are induced or exacerbated by a neuronal overactivity within a reciprocally excitatory frontothalamic circuit; (2) neuronal activity within this frontothalamic circuit is normally damped by an interposed inhibitory circuit involving the nucleus accumbens and limbic portions of the caudate nucleus (collectively, striatoaccumbens) and the ventral pallidum; (3) impaired functioning of this interposed inhibitory circuit will lessen the ability of the alcoholic to control cravings for alcohol or obsession-like thoughts about drinking; and (4) decreased control over these thoughts promotes their behavioral expression; that is, heavy or compulsive-like drinking.

II. Acute alcohol ingestion or-as a conditioned response to drinking - certain environmental or psychological cues normally associated with the individual's heavy drinking result in: (1) an increase in dopaminergic-inhibitory input from the ventral tegmentum to the striatoaccumbens; (2) a resultant decrease in normal inhibitory feedback through the striatoaccumbens and ventral pallidum to the thalamus; (3) a subsequent increase in reciprocally excitatory orbitothalamic activity; and (4) a resultant increase in craving for alcohol and/or a decrease the ability of the individual to control the behavioral expression of these thoughts. This process may be the result of an underlying, possibly heritable neurophysiological defect in these neuronal systems. The neuronal circuitry implicated in this process is schematically depicted in Fig. 1, and is collectively referred to as the fronto-striato-pallido- 
thalamo-frontal loop. Increases in dopaminergic activity within the nucleus accumbens have previously been implicated in the reinforcing properties of alcohol, ${ }^{4}$ cocaine, ${ }^{5,6}$ and heroin. ${ }^{6,7}$

Several tests of this hypothesis were proposed. In this study, we explore the effects of the D-2 antagonist haloperidol on measures of craving and impaired control in alcoholic subjects before and after administration of a priming dose of alcohol. It is reasoned that if the proposed disinhibitory effects of ventral tegmental-striatoaccumbal dopamine release associated with alcohol consumption are correct, then pharmacological blockade of dopamine postsynaptic receptors in the striatoaccumbens should diminish alcohol-induced craving, and diminish impaired control over drinking following alcohol consumption (or, conversely, increase the subject's ability to resist drinking additional alcohol). Furthermore, the effects of haloperidol on craving and control over alcohol consumption should be independent of any subjectively perceived side effects of this medication.

Past research has shown that administration of D-2 antagonists can decrease alcohol withdrawal symptoms and withdrawal-associated craving in the clinical setting ${ }^{8-}$ ${ }^{10}$ and decrease ethanol intake in free-feeding animals. ${ }^{4,11}$ Voluntary ethanol consumption in both animals and humans has also previously been reported to be decreased following administration of the D-2 agonists bromocryptine and apomorphine: this seemingly paradoxical effect may be the result of a medication-induced decrease in dopamine turnover secondary to presynaptic autoregulation, disruption of the normal high-rate drinking pattern during the initiation of a drinking bout, or side effects such as nausea., ${ }^{4,12}$ To our knowledge, however, this study is the first controlled study designed to determine whether

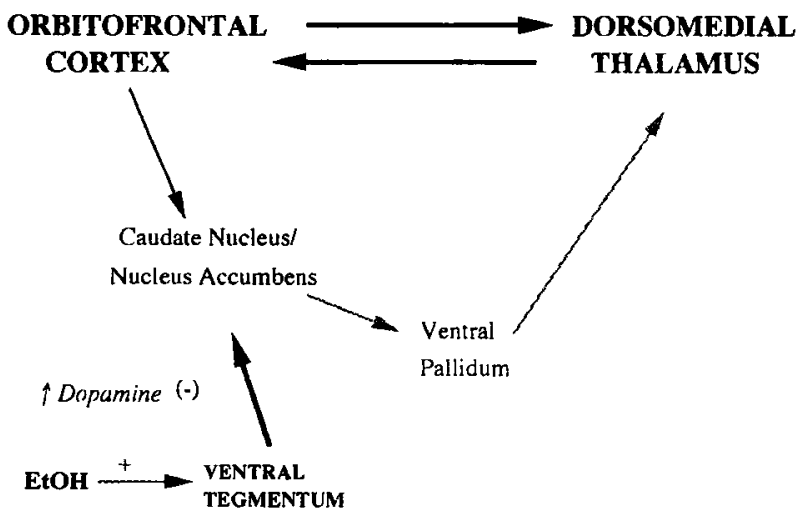

Fig. 1. Schematic diagram of the proposed relationship of neuronal activity to craving for alcohol and impaired control over alcohol consumption associated with alcohol ingestion. Alcohol-induced augmentation $(\mathrm{EtOH}+)$ of dopaminergic-inhibitory input ( $\uparrow$ dopamine -) from the ventral tegmentum to the striatoaccumbens (shown by larger, bold print) results in a decrease in inhibitory feedback through the striatoaccumbens and ventral pallidum to the thalamus (shown by smaller print, lighter arrows) and a consequent increase in orbitothalamic reciprocal activity (shown by larger, bold print). The decrease in normal inhibitory feedback to the thalamus is hypothesized to result in an increase in craving for alcohol and/or a decrease in the ability of the alcoholic to control the behavioral expression of these thoughts. In either case, impaired control over alcohol consumption or compulsive drinking behavior would result. a D-2 antagonist can specifically reduce measures of alcohol craving and impaired control following a priming dose of alcohol in human subjects who are not undergoing alcohol withdrawal.

\section{METHODS}

Sixteen subjects ( 10 men, 6 women; mean age 39, range 22-60) participated in this study. Subjects were selected on a volunteer basis from the University of Michigan and University of Alabama at Birmingham outpatient alcohol-disorders clinics. All study subjects were, therefore, engaged in, or entering a treatment program at the time of study participation, and all subjects returned to this program for continued treatment after completion of the experimental protocol. Informed consent was obtained from all subjects prior to study participation; this study was approved by the institutional review board and general clinical research center review board at each of the two universities. Subjects were paid $\$ 50$ for study participation. Prior to study participation, all subjects received a physical exam and laboratory evaluation that included liver function tests, electrolytes, blood urea nitrogen, creatinine, complete blood count, and urine pregnancy test for women of child-bearing potential.

All subjects satisfied DSM-III-R criteria for either alcohol dependence $(n=10)$ or alcohol abuse $(n=6)$. The last drink of alcohol taken by the subjects was between 1 and 14 weeks prior to participation in this project; therefore, neither individuals in the midst of alcohol intoxication or withdrawal, nor those who were achieving long-term abstinence were included in the study. All subjects reported that craving for alcohol and impaired control after one or two drinks were prominent components of their drinking history; this was quantified as follows: Subjects were asked: (1) "On a scale of 0 to 10 , how much do you usually crave an alcoholic beverage 1 to 2 days after your last drink, if 0 is none at all and 10 is extreme?" and (2) "On a scale of 0 to 10 , how difficult is it usually for you to stop drinking after just one or two small drinks, if 0 is extremely easy and 10 is extremely difficult?" A score of 5 or more for each question was required for participation. Degree of impaired control was also assessed from the clinical history: all subjects reported that they are generally unable to control their drinking once they have taken a drink, and that this problem occurred at least 10 times during the previous year.

The following subjects were excluded from participation: subjects with coexistent DSM III-R axis I psychiatric disorders, including other drug abuse; subjects having symptomatic medical problems or liver function tests greater than $150 \%$ of normal; subjects with a positive pregnancy test or any other reason to suspect pregnancy; and subjects taking any psychoactive medication or disulfiram within the previous 3 weeks. Ethnic and religious backgrounds were not factors in subject selection.

The experiment was designed as a randomized-crossover, doubleblind, placebo-controlled trial. All subjects were admitted for two voluntary overnight stays in our general clinical research center, $48 \mathrm{hr}$ apart; there was no experimental intervention between these admissions. Subjects were instructed to take nothing by mouth other than clear liquids during the $4 \mathrm{hr}$ preceding study participation. Subjects understood the nature of the double-blind crossover experimental design, but were not told about the experimental hypothesis or the predicted effects of haloperidol on the outcome measures until after completion of the experiment.

Upon presentation for study participation, subjects received a urine drug screen and blood alcohol concentration (BAC) by breath analysis (Alco-Sensor-III ${ }^{\otimes}$ breath intoximeter) to ensure that the subjects were drug- and alcohol-free at the start of the experiment. An assessment questionnaire (Fig. 2) was then administered to each subject to assess currently perceived mood, craving for an alcoholic beverage, expected degree of difficulty that would be encountered resisting drinking an alcoholic beverage if offered (difficulty resisting drinking), level of intoxication, thirst, capacity for experiencing pleasure, and sedation (assessment 0; Fig. 3). 
For each of the items below, please mark an $\mathbf{X}$ on the line at the place that best describes how you are feeling at this moment.

1. My mood right now is:

\begin{tabular}{|c|c|}
\hline $\begin{array}{l}\text { Extremely } \\
\text { Depressed }\end{array}$ & $\begin{array}{l}\text { Extremely } \\
\text { Happy }\end{array}$ \\
\hline
\end{tabular}

2. My level of desire or craving right now for an alcoholic beverage is:

$$
\begin{aligned}
& \text { None Extreme } \\
& 0-1-2-2-3--4-5-5-6-7-3-8-9-10
\end{aligned}
$$

3. If offered an alcoholic beverage right now, resisting drinking it would be:

$\begin{array}{ll}\begin{array}{l}\text { Extremely } \\ \text { Easy }\end{array} & \begin{array}{l}\text { Extremely } \\ \text { Difficult }\end{array} \\ 0-1-1-2-3-3-4-4-5-6-6-7-8-8-9-10\end{array}$

4. Right now, I feel:

$\begin{aligned} & \text { Not at all } \\ & \text { Intoxicated }\end{aligned}$
$0-1-1-2-3-3-4-5-6-7-8-9-9-10$

5. If $\$ 100$ were handed to me to keep (no strings attached) right now, I would be:

Not at all
Pleased $\begin{aligned} & \text { Extremely } \\ & \text { Pleased }\end{aligned}$

\begin{tabular}{|c|c|}
\hline $\begin{array}{l}\text { Not at all } \\
\text { Thissty }\end{array}$ & $\begin{array}{l}\text { Extremely } \\
\text { Thirsty }\end{array}$ \\
\hline
\end{tabular}

6. Right now, I feel:

\begin{tabular}{|c|c|}
\hline $\begin{array}{l}\text { Not at all } \\
\text { Sleepy }\end{array}$ & $\begin{array}{l}\text { Extremely } \\
\text { Sleepy }\end{array}$ \\
\hline
\end{tabular}

7. Right now, 1 feel:

Fig. 2. Assessment questionnaire for perceived mood, craving, resistance to drinking an alcoholic beverage if offered, intoxication, capacity for experiencing pleasure, thirst, and sedation. This questionnaire has been validated previously among alcoholic subjects, alcoholic subjects following exposure to alcohol, nonalcoholic subjects having major depressive disorder, nonalcoholic subjects having major depressive disorder who were taking tricyclic antidepressants, and norma subjects. The validation data showed the expected significant differences across groups in mood (item 1: depressed $<$ alcoholic $\approx$ normal; $\rho \leq 0.01$ ), craving and difficulty resisting drinking (items 2 and 3 : alcoholic $>$ depressed $\approx$ normal; $p \leq$ 0.01 ), and capacity for experiencing pleasure (item 5 : depressed $<$ alcoholic $\approx$ normal; $\rho \leq 0.01$ ); significantly greater ratings for thirst and sleepiness in depressed subjects who were taking tricyclic antidepressants than among all other subjects who were medication-free (items 6 and 7: $p \leq 0.02$ ); and significant increases in craving, difficulty resisting drinking, and intoxication in alcoholic subjects following exposure to alcohol (items 2, 3, and $4: \rho \leq 0.01$ ).

Aswesament $0 \rightarrow 5 \mathrm{~min} \rightarrow$ Haloperidol $0.015-0.025 \mathrm{mg} / \mathrm{kg}$ or saline i.v. $\rightarrow 15 \mathrm{~min} \rightarrow$

Alecoment $1 \rightarrow 5 \mathrm{~min} \rightarrow 0.4 \mathrm{mg} / \mathrm{kg}$ ethanol p.o. $\rightarrow 15 \mathrm{~min} \rightarrow$

Asecament $2 \rightarrow 5 \mathrm{~min} \rightarrow$ Optional $0.0-0.2 \mathrm{mg} / \mathrm{kg}$ ethand p.o. $\rightarrow 15 \mathrm{~min} \rightarrow$

Amessment $3 \rightarrow$ end of experiment

Assessment data collection items:

$0=$ Assessment Scales 1-7 (figure 2) and BAC (breath)

$1=$ Assessment Scales 1-7

$2=$ Assessment Scales 1-7 and BAC

3 = Assessment Scales 1-7, notation of optional beverage quantity consumed and reasons, BAC

Fig. 3. Flow diagram showing the sequence of experimental interventions and assessments.
Each subject then received haloperidol (diluted to $2 \mathrm{ml}$ volume) or 2 $\mathrm{ml}$ normal saline (placebo control) intravenously over approximately 15 sec. The order of haloperidol/saline administration was randomly determined by the investigational pharmacy: nine subjects received saline on the first night and haloperidol on the second, and seven subjects received haloperidol on the first night and saline on the second. In an effort to determine the dosage of haloperidol that would maximally affect measures of craving and impaired control without producing confounding side effects, $0.015 \mathrm{mg} / \mathrm{kg}$ haloperidol was administered to the first four subjects, $0.020 \mathrm{mg} / \mathrm{kg}$ to the next eight subjects, and $0.025 \mathrm{mg} / \mathrm{kg}$ to the last four subjects. A starting dosage of $0.015 \mathrm{mg} / \mathrm{kg}$ haloperidol was chosen, because physiological effects in humans resulting from central D-2 postsynaptic receptor antagonism following haloperidol administration become apparent in the 0.007 to $0.025 \mathrm{mg} / \mathrm{kg}$ dosage range. ${ }^{13-19}$ Following haloperidol/saline administration, each subject rested for 15 min to allow time for uptake of haloperidol into the brain. ${ }^{20}$ At this time, the assessment questionnaire was repeated (assessment 1), and passive motor tone in the upper extremities was assessed on a scale of 0 to 4 (0 $=$ no resistance to passive motion, $4=$ rigid). Additionally, subjects were asked whether they believed the injection contained placebo or active drug based on the perceived of the effects of the injection.

Over the next $5 \mathrm{~min}$, each subject was required to drink his or her favorite alcoholic beverage-that which he or she believed would most likely induce a desire for more of this beverage-containing $0.4 \mathrm{~g} / \mathrm{kg}$ ethanol. When necessary, this beverage was fortified with $95 \%$ ethanol to limit the volume of beverage to $350 \mathrm{ml}$. The subject then rested for another $15 \mathrm{~min}$, at which time the assessment questionnaire was readministered (assessment 2) and, immediately following, the BAC was again measured by breath analysis.

The subject was then offered a choice of a second alcoholic beverage (same as the first but containing $0.2 \mathrm{~g} / \mathrm{kg}$ ethanol), a glass of water, or no beverage. The subject was permitted to drink as much of the second alcoholic beverage as he or she desired over a period not to exceed 5 $\min$. The quantity of alcoholic beverage consumed at the end of the 5min period (scored as 0 for choice of water or no beverage) along with the reported reason for choosing that quantity were noted. Fifteen minutes later, the assessment questionnaire was repeated for a final time (assessment 3), and the BAC was again measured. At this time, the subject was again asked whether he or she believed the injection contained placebo or active drug.

Approximately 2 weeks following the experiment, each subject discussed his or her reactions to the experiment-and especially to the alcohol administration-with the principal investigator (J.G.M.). The goal of this discussion was to use the knowledge gained from drinking in the controlled setting about the effects of alcohol consumption on mood, expectations, craving, and impaired control to help the subject understand more completely his or her reactions to alcohol consumption and reasons for using this drug.

The outcome variables to be analyzed are the seven continuous assessment scales (questions 1-10, Fig. 2), the BACs following alcohol consumption, and the quantity of the second alcoholic beverage consumed. The assessment scales for craving and perceived ability to resist drinking an alcoholic beverage if offered (questions 2 and 3, respectively), and the quantity consumed of the second alcoholic beverage are the primary dependent variables, hypothesized to be specifically affected by haloperidol. The other assessment questionnaire items, BACs, ages of the subjects, subject gender, type of alcohol problem (abuse or dependence), and the duration of abstinence prior to study participation were treated as confounding variables.

The change in each questionnaire-item rating from baseline (assessment 0 ) to each of the three postinjection assessments was determined for each subject under both the haloperidol and control conditions. The within-subject difference in change scores for each question at each assessment was compared between experimental conditions (haloperidol versus saline) using paired $t$ tests. Within-subject paired $t$ tests were also used to compare the effects of haloperidol and saline on motor tone and optional alcohol consumption. Analyses of variance were used to com- 
pare the effects of saline and haloperidol on the primary dependent variables across time adjusted for intersubject variability. Analysis of covariance and linear regression were used to assess the effects of the potential confounding variables on the primary dependent variables. Order effects in the crossover design were evaluated using a $t$ test for independent samples. All statistical tests use two-tailed probabilities at the 0.05 significance level.

\section{RESULTS}

Significant increases in subjectively rated craving for alcohol (question 2, Fig. 2) and difficulty resisting drinking (question 3, Fig. 2) occurred following the priming dose of alcohol (assessment 2) when subjects were pretreated with the saline control $(F=12.3$, df $1 / 31, p<0.01 ; F=$ 24 , df $1 / 31, p<0.001$, respectively). Ratings of craving and difficulty resisting drinking remained significantly elevated at assessment 3 when subjects were pretreated with saline $(F=7.4,1 / 31, p=0.01 ; F=4.5, d f 1 / 3, p=$ 0.05 , respectively). In marked contrast to these results, reported levels of craving and difficulty resisting drinking following pretreatment with haloperidol showed no significant changes over time except for a significant decrease in craving relative to baseline at assessment $4(F=4.9, d f$ $1 / 31, p=0.05$ ). The differential effects of haloperidol and saline on these outcome measures are apparent in the graphical display of the change scores for these variables shown in Figs. 4 and 5: the change scores for each question are derived by subtracting the assessment 0 (baseline) rating from each of the subsequent ratings for that question. For reference, mean craving scores at assessment 0 were 4.2 preceding saline administration, and 5.1 preceding haloperidol administration ( $p=\mathrm{NS}$ ); and mean scores for difficulty resisting drinking at assessment 0 were 4.0 preceding saline administration, and 4.9 preceding haloperidol administration ( $p=\mathrm{NS})$.

The average within-subject differences between the saline and haloperidol condition for craving (Fig. 4) were -1.2 at assessment $1(t=-1.4, d f=15, p=0.18),-2.8$ at assessment $2(t=-3.1, d f=15, p=0.007)$, and -2.9 at assessment $3(t=-3.0, d f=15, p=0.009)$. The average within-subject differences between the saline and haloperidol condition for difficulty resisting drinking (Fig. 5) were -0.9 at assessment $1(t=-0.91, d f=15, p=0.05),-2.4$ at assessment $2(t=-3.4, d f=15, p=0.004)$, and -2.8 at assessment $3(t=-2.6, d f=15, p=0.02)$. Subjects also consumed an average of about $26 \%$ less optional (second beverage) alcohol when pretreated with haloperidol than when pretreated with saline $(t=-2.2, d f=15, p$ $=0.04$; Fig. 6 ).

There were no significant interaction effects between experimental condition (haloperidol versus saline) and time for any of the other outcome variables except for reported levels of sedation (question 7; Fig. 2). Following haloperidol administration, there were significant increases in reported levels of sedation relative to those reported following saline pretreatment. The average within-subject differences for sedation between the saline and haloperidol conditions were +1.4 at assessment 1 ( $t$ $=2.8, d f=15, p=0.014),+2.4$ at assessment $2(t=3.3$, $d f=15, p=0.004)$, and +2.4 at assessment $3(t=3.5, d f$ $=15, p=0.003$ ). Overt sedation, however, did not occur and there were no independent correlations between reported levels of sedation and craving, difficulty resisting drinking, or optional alcohol consumption $\left(r^{2}<0.1, p>\right.$ 0.1 for all comparisons). Additionally, subjects generally had difficulty distinguishing injected haloperidol from saline: the agent administered was misclassified by the subjects in $34 \%$ of the cases at assessment 1 , and in $31 \%$ of the cases at assessment $3\left(\chi^{2}<3.2, d f=1, p>0.08\right)$.

No significant differences were found in the relative effects of haloperidol on craving, difficulty resisting drinking, optional alcohol consumption, and sedation as a function of haloperidol dosage $\left(r^{2}<0.05, p>0.2\right.$ for all comparisons), and no order effect of haloperidol/saline administration was found on the primary outcome variables. Measured BACs averaged $50.7 \mathrm{mg} \%$ following the first drink of $0.4 \mathrm{~g} / \mathrm{kg}$ ethanol, and $71.5 \mathrm{mg} \%$ following

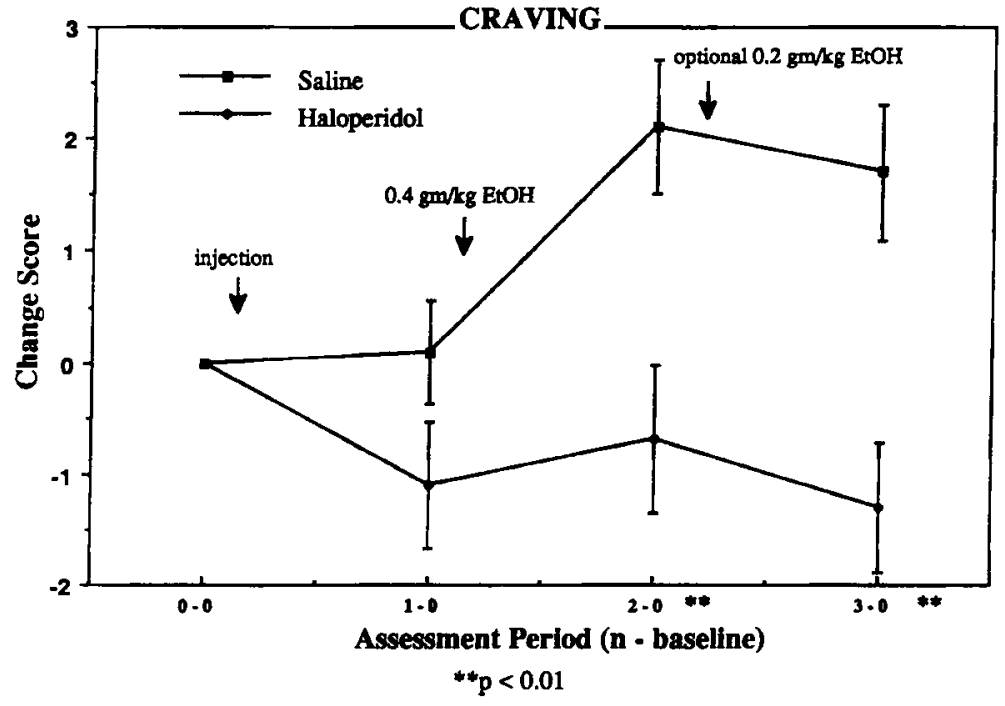

Fig. 4. Change scores for craving (question 2, Fig. 2) from baseline (assessment 0 ) to the assessments following injection (assessment 1), following $0.4 \mathrm{~g} / \mathrm{kg}$ beverage ethanol (assessment 2), and following 0.0 $0.2 \mathrm{~g} / \mathrm{kg}$ optional ethanol (assessment 3). Error bars show the standard errors of the mean (SEM). Mean craving scores at assessment 0 were 4.2 preceding saline administration, and 5.1 preceding haloperidol administration $(p=N S)$. 


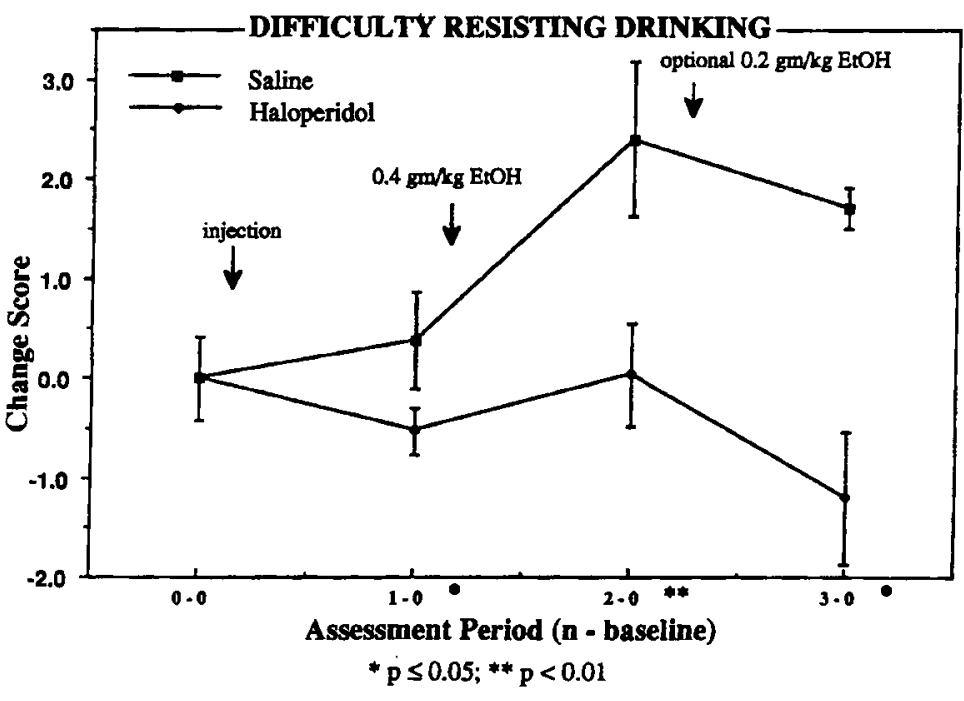

Fig. 5. Change scores for perceived ability to resist drinking an alcoholic beverage if offered (question 3, Fig. 2), depicted as in Fig. 4. Mean resistance scores at assessment 0 were 4.0 preceding saline administration, and 4.9 preceding haloperidol administration $(\rho=N S)$.

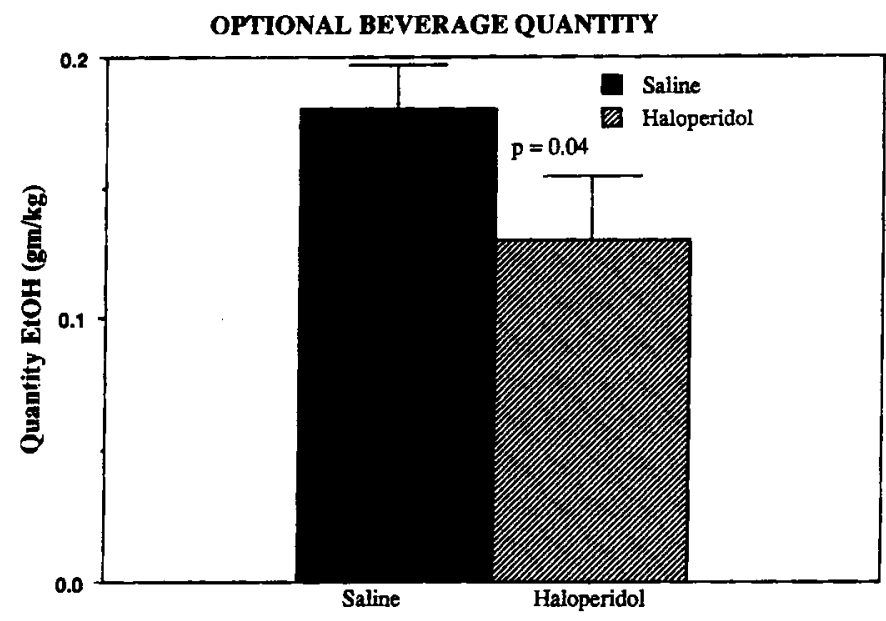

Fig. 6. Quantity of optional alcoholic beverage consumed (g/kg EtOH) following saline administration (left) and haloperidol administration (right).

the second drink of variable quantity $(0-0.2 \mathrm{~g} / \mathrm{kg}$ ethanol). All BACs were 0 at the start of the experiments. BACs were not independently associated with any of the primary outcome measures $\left(r^{2}<0.05, p>0.4\right)$. Additionally, no independent effects on the outcome variables were found as a function of subject age, sex, duration of abstinence, and type of alcohol problem (abuse versus dependence); it is, however, recognized that there may be insufficient statistical power to detect small effects from these factors.

The reasons provided by the subjects for choosing to drink-or not to drink-the optional second beverage were informative. Following saline administration, all but two subjects consumed the full amount of optionally available alcohol. The two who did not reported that they simply "weren't in the mood," and that the ambient conditions were not conducive to enjoying additional alcohol. Following haloperidol administration, five subjects turned down the second drink entirely and one subject drank only one-quarter of this beverage. Three of these six subjects commented that their lack of desire to continue drinking alcohol was very unusual, but they could not explain what was different about the current situation that would cause an unprecedented loss of interest in continued drinking; each suspected that this was an effect of the injection, although none were certain they had received haloperidol. Another subject who declined the second beverage said that his usual desire to continue drinking was simply absent, and he explained this on the basis of feeling "adequately relaxed" following the first drink. The sixth subject could find no explanation for refusal of the second beverage other than, "I just don't feel like drinking anymore."

\section{DISCUSSION}

The significant increases in subjectively rated craving for alcohol and difficulty resisting drinking that occurred following the priming dose of alcohol under the saline condition are consistent with the subjects' reported histories of impaired control over alcohol consumption in the naturalistic setting. In contrast, following pretreatment with haloperidol, subsequent exposure to alcohol did not cause the usual increases in craving and difficulty resisting drinking; reported levels of craving actually decreased relative to baseline at the final assessment period. That subjects also chose to drink less of the optionally available alcohol following haloperidol pretreatment than under the saline condition indicates that pretreatment with haloperidol also affects the behavioral consequence of these subjective questionnaire measures.

The findings of this study support the hypothesis that craving and impaired control in alcoholic individuals are induced or exacerbated by the dopaminergic effects of intoxication (and possibly a conditioned response to psychological or social cues associated with drinking), and that craving and impaired control can be diminished by administration of a pharmacologic D-2 antagonist prior to alcohol exposure. The study results are consistent with the effect of D-2 antagonists on free-access alcohol drink- 
ing in animals and support the hypothesis derived from these studies that the D-2 antagonist acts at the level of the nucleus accumbens and interferes with conditions necessary to maintain drinking during the early parts of the drinking bout. ${ }^{4}$ The relative inability of the subjects to identify accurately whether they received haloperidol or placebo, the lack of a significant association between haloperidol-induced sedation and the primary outcome measures, the absence of other measurable side effects from haloperidol, and the reasons given by the subjects for choosing to forego additional alcohol consumption all argue against the effect of haloperidol on craving, difficulty resisting drinking, and optional alcohol consumption being an epiphenomenon related to side-effects of this medication.

Although the study findings are consistent with the hypothesized involvement of ventral tegmental-striatoaccumbal pathways in craving and impaired control over alcohol consumption, it is not possible from this experiment to implicate directly this or associated circuits in the mediation of the observed effects of haloperidol on the primary outcome measures. These effects could, for example, result from interference with dopaminergic neurotransmission through the classically described reward or pleasure circuits involving mesocortical (tegmental-frontal) dopaminergic projections, the hypothalamus, the amygdala, and septal areas, without producing a downstream effect within the fronto-striato-pallido-thalamofrontal loop via the nucleus accumbens. ${ }^{3,21,22}$ Future studies will be necessary to link the neuropharmacological mechanisms of craving and impaired control in humans with specific anatomic regions.

Additionally, the results of this study do not allow the conclusion that craving and impaired control over alcohol drinking are exclusively modulated by dopaminergic systems. Past studies have shown that other neurotransmitter systems-for example, the opioidergic ${ }^{23}$ and serotonergic systems ${ }^{24}$-are also associated with alcohol consummatory behaviors. Taken together, the data strongly support that the regulation of alcohol consumption involves an interaction between dopaminergic and other neurotransmitter systems; extensive interactions between dopaminergic and opioidergic systems in the ventral tegmental area and nucleus accumbens, for example, are well-described. ${ }^{25}$

The relative absence of significant observed and reported side effects from haloperidol (with the exception of reported sedation) and the relative inability of subjects to differentiate injected haloperidol from saline were unexpected. We questioned, therefore, whether this finding might reflect the altered dopaminergic neuronal activity or abnormal D-2 postsynaptic receptor sensitivity described in animal models of alcoholism. ${ }^{26,27}$ To explore this possibility further, we performed a companion study in which we administered $0.020 \mathrm{mg} / \mathrm{kg}$ haloperidol intravenously to 16 normal, nonalcoholic control subjects and collected the same information at the same time periods relative to injection as in the alcohol study. This experiment was also a randomized-crossover ( 2 days apart), double-blind, placebo-controlled study. Subjects in this experiment did not receive alcohol; all BACs at the start of the experiments were 0 . Institutional review board approval was also obtained for this study.

Results of the companion study showed that, at the first assessment following the injection (assessment 1), there were no significant differences between the alcoholic subjects and normal controls in motor tone, ability of the subject to identify accurately the injected material (the agent administered was misclassified by the normal subjects in $38 \%$ of cases at this assessment), or changes on any items of the assessment questionnaire. At assessment $3,50 \%$ of the control subjects misclassified the administered agent. Because the alcoholic subjects received alcohol following the first postinjection assessment and the control subjects did not, further comparison of outcome measures beyond the first postinjection assessment was not possible. The results of the companion study suggest, therefore, that the relative lack of observed and reported side effects from the injected haloperidol in the alcoholic subjects is not unique to this population and does not necessarily reflect the abnormal D-2 postsynaptic receptor sensitivity described in animal models of alcoholism.

In conclusion, pretreatment with haloperidol produced favorable changes in subjectively rated alcohol craving and difficulty resisting drinking, and also decreased the amount consumed of optionally available alcohol without causing undesirable side effects. In addition to the research implications of these findings previously discussed, these results also suggest that low doses of D-2 antagonists taken orally in response to strong desires to drink may, in certain cases, reduce impaired control over drinking in the ambulatory setting. Although the risk of serious dystonic reactions and tardive dyskinesia associated with low doses of intermittently administered D-2 antagonists is small, ${ }^{28}$ it will be important to determine whether there are specific subtypes of heavy drinkers for which administration of a D-2 antagonist might carry a particularly favorable riskbenefit ratio before the widespread use of these agents can be recommended in this population. The recent development of dopamine antagonists that lack many of the undesirable neurological effects of the conventional agents offers additional hope that a useful role for the dopamine antagonists in the treatment of chronic, heavy drinking might ultimately be found.

\section{ACKNOWLEDGMENTS}

We thank Herman H. Samson, Ph.D., Director, University of Washington Alcohol and Drug Abuse Institute, for his very helpful scientific guidance. 


\section{REFERENCES}

1. Institute of Medicine: What is being treated?, in Broadening the Base of Treatment for Alcohol Problems. Washington, DC, National Academy Press, 1990, pp 23-41

2. Modell JG, Mountz JM, Beresford TP: Basal ganglia/limbic striatal and thalamocortical involvement in craving and loss of control in alcoholism. J Neuropsychiatry Clin Neurosci 2:123-144, 1990

3. Koob GF: Drugs of Abuse: Anatomy, pharmacology and function of reward pathways. Trends Pharm Sci 13:177-184, 1992

4. Samson HH, Tolliver GA, Haraguchi M, Hodge CW: Alcohol self-administration: role of mesolimbic dopamine, in Kalivas PW, Samson HH (eds): The Neurobiology of Drug and Alcohol Addiction. New York, New York Academy of Sciences Press, 1992, pp 242-253

5. Roberts DCS, Koob GF, Klonoff P, Fibiger HC: Extinction and recovery of cocaine self-administration following 6-hydroxydopamine lesions of the nucleus accumbens. Pharmac Biochem Behav 12:781-787, 1980

6. Zito KA, Vickers G, Roberts CS: Disruption of cocaine and heroin self-administration following kainic acid lesions of the nucleus accumbens. Pharmac Biochem Behav 23:1029-1036, 1985

7. Spyraki C, Fibiger HC, Phillips AG: Attenuation of heroin reward in rats by disruption of the mesolimbic dopamine system. Psychopharmacology 79:278-283, 1983

8. Anokhina IP: Changes in catecholamine and opiate systems in the state of pathological alcoholic motivation, in Sudakov KV (ed.): Systems Research in Physiology, vol 1: Motivation in Functional Systems. New York, Gordon \& Breach, Science Publishers, 1987, pp 243255

9. Palestine ML, Alatorre E: Control of acute alcoholic withdrawal symptoms: A comparative study of haloperidol and chlordiazepoxide. Curr Ther Res 20:289-299, 1976

10. Greenberg LA, Rosenfeld JE: Haloperidol in the treatment of acute alcoholism. Psychosomatics 10:172-175, 1969

11. Pfeffer AO, Samson HH: Haloperidol and apomorphine effects on ethanol reinforcement in free feeding rats. Pharmacol Biochem Behav 29:343-350, 1988

12. Borg V: Bromocriptine in the prevention of alcohol abuse. Acta Psychiatr Scand 68:100-110, 1983

13. Saarialho-Kere U: Psychomotor, respiratory and neuroendocrinological effects of nalbuphine and haloperidol, alone and in combination, in healthy subjects. $\mathrm{Br} \mathrm{J}$ Clin Pharmacol 26:79-87, 1988

14. Hays SE, Rubin RT: Differential prolactin responses to haloper- idol and TRH in normal adult men. Psychoneuroendocrinology 6:4552,1981

15. Copolov DL, Keks NA, Kulkarni J, et al: Prolactin response to low-dose haloperidol challenge in schizophrenic, non-schizophrenic psychotic, and control subjects. Psychoneuroendocrinology 15:225-231, 1990

16. Frey S, Bente G, Fuchs A, et al: Spontaneous motor activity in healthy volunteers after single doses of haloperidol. Int Clin Psychopharmacol 4:39-53, 1989

17. Rubin RT, Hays SE: Variability of prolactin response to intravenous and intramuscular haloperidol in normal adult men. Psychopharmacology (Berlin) 61:17-24, 1979

18. Frey S, Bente G, Fuchs A, et al: Department of Psychology, University of Duisburg, FRG. Spontaneous motor activity in healthy volunteers after single doses of haloperidol. Int Clin Psychopharmacol 4:39-53, 1989

19. Murburg MM, Paly D, Wilkinson CW, et al: Haloperidol increases plasma beta endorphin-like immunoreactivity and cortisol in normal human males. Life Sci 39:373-381, 1986

20. Holley FO, Magliozzi JR, Stanski DR, et al: Haloperidol kinetics after oral and intravenous doses. Clin Pharm Ther 33:477-484, 1983

21. Kosten TR: Neurobiology of abused drugs. Opioids and stimulants. J Nerv Ment Dis 178:217-227, 1990

22. McGeer PL, Eccles JC, McGeer EG: Molecular Neurobiology of the Mammalian Brain. New York, Plenum Press, 1987, pp 437-439 \& 527-533

23. Volpicelli JR, Uln RR, Hopson $\mathrm{N}$ : Alcohol drinking in rats during and following morphine injections. Alcoholism 8:282-292, 1991

24. Naranjo CA, Sellers EM: Serotonin uptake inhibitors attenuate ethanol intake in problem drinkers. Recent Dev Alcohol 7:255-266, 1989

25. Stinus L, Cador M, Le Moal M: Interaction between endogenous opioids and dopamine within the nucleus accumbens, in Kalivas PW, Samson HH (eds): The Neurobiology of Drug and Alcohol Addiction. New York, New York Academy of Sciences Press, 1992, pp 254-271

26. Balldin J, Alling C, Gottfries CG, et al: Changes in dopamine receptor sensitivity in humans after heavy alcohol intake. Psychopharmacology 86:142-146, 1985

27. Balldin JI, Berggren UC, Lindstedt G: Neuroendocrine evidence for reduced dopamine receptor sensitivity in alcoholism. Alcohol Clin Exp Res 16:71-74, 1991

28. Casey DE: Neuroleptic drug-induced extrapyramidal syndromes and tardive dyskinesia. Schizophr Res 4:109-120, 1991 